\title{
Precificação de Produtos e Ancoragem do Dígito Esquerdo: uma Análise da Percepção de Futuros Gestores
}

Graduação em Administração em andamento pela Universidade Federal de Uberlândia Av. João Naves de Ávila, - UFU E-mail: jose.lara@outlook.com

Fernanda Francielle de Oliveira Malaquias Pós-Doutorado em Sistemas de Informações Gerenciais pela DePaul University, Chicago/Estados Unidos Professora da Universidade Federal de Uberlândia - UFU Av. João Naves de Ávila, 2121. Santa Mônica. Uberlândia/MG. CEP: 38408-100 E-mail: fernandafrancielle@gmail.com

Alexsandra Faria da Silva Graduação em Administração em andamento pela Universidade Federal de Uberlândia Av. João Naves de Ávila, 2121. Santa Mônica. Uberlândia/MG. CEP: 38408-100 E-mail: alexsandra.faria26@gmail.com

Ana Carolina Alves de Souza Graduação em Administração em andamento pela Universidade Federal de Uberlândia Av. João Naves de Ávila, 2121. Santa Mônica. Uberlândia/MG. CEP: 38408-100 E-mail: anacarolinaalvesdesouza@hotmail.com

Marcielle Cristina Pessoa Ribeiro Graduação em Administração em andamento pela Universidade Federal de Uberlândia Av. João Naves de Ávila, 2121. Santa Mônica. Uberlândia/MG. CEP: 38408-100 E-mail: marciellecris@hotmail.com

\section{RESUMO}

Uma das estratégias de precificação que tem sido muito utilizada pelas empresas consiste na fixação de preços terminados em 99. Como os consumidores tendem a ancorar a percepção dos preços nos dígitos à esquerda, essa estratégia de fixar preços terminados em 99 pode levar a uma subestimação dos preços, o que é conhecido como Ancoragem do Dígito Esquerdo. Nesse contexto, o presente estudo tem como objetivo identificar qual a percepção dos estudantes de Administração, enquanto futuros gestores, sobre a exploração da Ancoragem do Dígito Esquerdo na precificação de produtos. Para a realização do estudo, foi adotada uma abordagem qualitativa. Os 
Precificação de Produtos e Ancoragem do Dígito Esquerdo: uma Análise da Percepção de Futuros

Gestores

José Lucas Lara de Melo, Fernanda Francielle de Oliveira Malaquias, Alexsandra Faria da Silva, Ana

Carolina Alves de Souza, Marcielle Cristina Pessoa Ribeiro

dados foram coletados por meio de entrevistas semiestruturadas que foram analisadas por meio da técnica de Análise de Conteúdo. Os resultados encontrados apontam que os estudantes entrevistados apresentam uma visão, em maior parte, positiva sobre esse tipo de precificação, demonstrando crenças de que ela pode incrementar as vendas por causa da imagem que transmite. Eles também acreditam que essa estratégia de precificação muitas vezes é realizada de forma intuitiva pelos gestores. Por fim, todos os entrevistados apontaram que explorariam a ancoragem do dígito esquerdo na precificação dos produtos, caso tivessem uma empresa de varejo.

Palavras-chave: Preços terminados em 99. Estratégias de precificação. Heurística da Ancoragem.

\section{Products Pricing and the Left Digit Anchoring: An Analysis of Future Managers Perception}

\section{ABSTRACT}

One of the pricing strategies that has been widely used consists in fixing prices ending in 99. As consumers tend to anchor the perception of prices in the left digit, this strategy of fixing prices ending in 99 can lead to an underestimation of prices, what is known as Left Digit Anchoring. In this context, the objective of this study is to identify the perception of business students, as future managers, about the use of left digit anchoring in the process of products pricing. We adopted a qualitative approach and the data were collected through semi-structured interviews. In order to analyze the data we used the Content analysis technique. The results showed that the students interviewed, in general, have a positive vision about this kind of pricing strategy; they believe that this strategy can contribute with the sales volume due the image it transmits. They also believe that this pricing strategy is often done intuitively by managers. Finally, all respondents indicated that they could explore the left digit anchoring in the pricing process if they had a firm.

Keywords: Prices finished in 99. Pricing strategies. Heuristic of anchoring.

\section{INTRODUÇÃO}

Dentre os compostos que envolvem a oferta de um produto está o preço, que é o valor monetário que uma mercadoria assume. O preço possui grande influência no processo de decisão do consumidor, pois este irá comparar se a mercadoria tem um valor compatível com o preço que é cobrado por ela (KOTLER; KELLER, 2013). 
Precificação de Produtos e Ancoragem do Dígito Esquerdo: uma Análise da Percepção de Futuros

Gestores

José Lucas Lara de Melo, Fernanda Francielle de Oliveira Malaquias, Alexsandra Faria da Silva, Ana Carolina Alves de Souza, Marcielle Cristina Pessoa Ribeiro

A formação do preço de venda de um produto passa por diversas fases no ponto de vista da gestão empresarial. Um dos desafios que as empresas enfrentam no cenário competitivo atual refere-se ao estabelecimento de preços de venda que sejam suficientes para cobrir os custos necessários para oferecer seus produtos ou serviços (WIENHAGE, ROCHA e SCARPIN, 2012). Tem-se, assim, um papel relevante da contabilidade gerencial, de forma que os custos dos produtos sejam estimados adequadamente, o preço de venda seja formado e a margem de contribuição possa ser conhecida pelos usuários da informação contábil, o que auxiliará na gestão do negócio (SILVA FILHO et al., 2015).

Segundo Blackwell, Miniard e Engel (2005), o consumidor passa por 7 estágios durante seu processo de compra, sendo eles o reconhecimento da necessidade, a busca por informações, a avaliação de alternativas pré-compra, a compra, o consumo, a avaliação pós-consumo e o descarte. Ainda segundo os autores, o processo de compra é afetado por vários fatores, dentre eles a disponibilidade de tempo que o comprador possui e os recursos cognitivos que ele utiliza durante o processo.

Assim, para compras de baixo risco ou compras em que o consumidor tem pouco tempo, acontecem processos de heurísticas, que são "atalhos mentais", em que a pessoa, diante de uma grande variedade de estímulos e informações, simplifica todos esses dados a fim de poder tomar uma decisão mais rápida e, ainda, com certo grau de racionalidade (MARCELINO; BRUNI, 2012).

O foco desta pesquisa é a heurística da ancoragem que "consiste em adotar um valor inicial como âncora para um julgamento posterior" (PAIXÃO; CARVALHO JÚNIOR; BRUNI, 2010, p. 440). Assim, a ancoragem do dígito esquerdo consiste em ancorar a percepção dos preços nos dígitos à esquerda. Por exemplo, o consumidor vê um preço de 10,99 como sendo apenas 10, por mais que o valor esteja mais próximo de 11 do que de 10 (PAIXÃO; CARVALHO JÚNIOR; BRUNI, 2010).Tendo em vista que o processamento de informações é realizado da esquerda para a direita, "a truncagem de informações sobre preços é susceptível de conduzir à significativa subestimação dos 
Precificação de Produtos e Ancoragem do Dígito Esquerdo: uma Análise da Percepção de Futuros

Gestores

José Lucas Lara de Melo, Fernanda Francielle de Oliveira Malaquias, Alexsandra Faria da Silva, Ana Carolina Alves de Souza, Marcielle Cristina Pessoa Ribeiro

preços terminados em 99 não apenas durante as comparações de preços imediatas, mas também em futuros julgamentos de preços" (CARVER; PADGETT, 2012, p. 499).

Devido à imagem específica que preços terminados em 99 passam e à exploração da desatenção dos consumidores que desejam economizar com o custo de processamento de informação, a fixação de preços terminados em 99 tem se tornado uma prática comum em muitos mercados de produtos de consumo (HACKL; KUMMER; WINTER-EBMER, 2014). Essa prática, quando combinada com a gestão de custos, pode fazer com que as empresas comercializem suas mercadorias, atingindo um nível mínimo de rentabilidade, conforme exigido pelos detentores do capital investido na organização. Assim, a gestão de custos contribui positivamente com a competitividade (SILVA FILHO et al., 2015) das empresas, desde que adotada de maneira adequada. De um lado, por meio do auxílio no controle (MARTINS, 2003), a contabilidade de custos poderá evidenciar a formação do custo de um determinado produto, permitindo verificar se o seu preço de venda permite ainda a obtenção de uma margem de contribuição. De outro lado, a ancoragem do dígito esquerdo pode ser utilizada para que o preço oferecido ao consumidor mostre-se mais "atrativo".

Considerando que os consumidores utilizam processos de heurística no seu processo decisório e que tal comportamento é um ponto que geralmente é explorado pelos gestores na precificação de produtos e serviços, tem-se a seguinte questão de pesquisa: Como os estudantes de Administração, futuros gestores, percebem a exploração da ancoragem do dígito esquerdo na precificação? Com base no que foi apresentado, o objetivo geral deste estudo consiste em evidenciar como os estudantes de Administração percebem a exploração da ancoragem do dígito esquerdo na precificação de produtos.

Apesar da vasta literatura a respeito do tema, a maioria dos estudos analisa esse tipo de precificação sob a ótica dos consumidores. Esse estudo visa complementar a literatura existente, analisando essa forma de precificação sob a ótica de futuros gestores. Além disso, a discussão realizada neste estudo permite avaliar como a gestão de custos, quando realizada de maneira adequada, pode ser combinada com 
Precificação de Produtos e Ancoragem do Dígito Esquerdo: uma Análise da Percepção de Futuros

Gestores

José Lucas Lara de Melo, Fernanda Francielle de Oliveira Malaquias, Alexsandra Faria da Silva, Ana

Carolina Alves de Souza, Marcielle Cristina Pessoa Ribeiro

estratégias de precificação de forma que o preço de venda seja suficiente para cobrir os custos e ainda tenha características que possam contribuir com a aquisição dos produtos por parte dos clientes.

\section{REVISÃO DA LITERATURA}

\subsection{Estratégias de Precificação e Formação de Preços}

A contabilidade de custos representa "[...] uma atividade que produz informações de custos para alguém que tem, por função, a gestão dessas informações. Como resultado, temos a gestão de custos, que pode ser operacional, decisória, estratégica, analítica, controladora ou tantos outros qualificativos, dependendo das necessidades de quem solicitou a preparação das informações" (LEONE e LEONE, 2007, p. 15). A contabilidade de custos representa um instrumento para fins gerenciais e possui duas funções relevantes: o auxílio ao controle e o auxílio no processo de tomada de decisões (MARTINS, 2003).

Por meio da análise dos custos, uma empresa pode, por exemplo, decidir entre terceirizar a produção de determinada mercadoria ou produzir essa mercadoria internamente (BAPTISTA, SILVA e ALVAREZ, 2016); ao optar por produzir

internamente, a gestão dos custos favorece a qualidade das decisões e a competitividade da empresa (SILVA FILHO et al., 2015).

É importante ainda apontar que o aumento da competitividade empresarial exige que as empresas conheçam suas estruturas internas e o preço final dos produtos/serviços que comercializa; com isso, a gestão estratégica de custos contribui para que as empresas consigam se manter no mercado (MOREIRA et al., 2015).

No tocante à formação de preços, o conhecimento dos custos se faz vital, no entanto, isso não basta, pois existem outros fatores que influenciam na formação dos preços. Os administradores da empresa devem ter o entendimento pleno do mecanismo do mercado no qual a entidade está inserida e alinhar tal entendimento à gestão de 
Precificação de Produtos e Ancoragem do Dígito Esquerdo: uma Análise da Percepção de Futuros

Gestores

José Lucas Lara de Melo, Fernanda Francielle de Oliveira Malaquias, Alexsandra Faria da Silva, Ana Carolina Alves de Souza, Marcielle Cristina Pessoa Ribeiro

custos e às estratégias definidas pela mesma para a formação do preço de venda (SILVA FILHO et al., 2015, p. 113).

As estratégias de formação do preço de venda adotadas por uma empresa podem afetar diretamente sua lucratividade e a imagem que os consumidores têm do produto ou serviço que ela fornece (MILAN et al., 2013). Uma estratégia de preços sólida deve considerar e analisar cuidadosamente as forças atuantes no mercado, a sensibilidade aos preços por parte dos consumidores, a situação interna da empresa e as interações com as empresas concorrentes (TORRES; MARTINS, 2006).

Conforme apontou a revisão da literatura realizada por Ahmetoglun, Furnham e Fagan (2014), os vendedores podem influenciar a percepção e as decisões de compra dos consumidores dependendo da forma em que os preços são evidenciados. A maneira com a qual as empresas determinam seus preços não afeta somente a demanda, mas também o modo como os compradores consumem o produto e/ou serviço, de forma a influenciar no estabelecimento, na conservação e na consolidação de relacionamentos estáveis entre o fornecedor e o consumidor (KOTLER; KELLER, 2013).

Conforme já apontado anteriormente, a determinação do preço de venda dos produtos com base apenas em informações de mercado não se mostra a maneira mais adequada para as empresas. Mesmo aquelas instituições que possuem pouco poder de gestão sobre o preço de venda final de seus produtos, conhecer sua estrutura interna de custos faz com que ineficiências possam ser detectadas e a margem de contribuição possa ser otimizada, o que pode ser administrado por meio da metodologia do target costing, ou custeio-alvo (WIENHAGE, ROCHA e SCARPIN, 2012).

A teoria contemporânea da tomada de decisão gerencial enfatiza que, no cenário atual em que há muitas informações e pouco tempo para se decidir, torna-se impossível a tomada de decisões completamente racionais, de forma que a intuição e o senso comum têm grande valor durante esse processo (MOTTA, 1998). 
Precificação de Produtos e Ancoragem do Dígito Esquerdo: uma Análise da Percepção de Futuros

Gestores

José Lucas Lara de Melo, Fernanda Francielle de Oliveira Malaquias, Alexsandra Faria da Silva, Ana Carolina Alves de Souza, Marcielle Cristina Pessoa Ribeiro

\subsection{Estudos Anteriores}

Segundo Diamantopoulos (2003), as pesquisas científicas realizadas sobre precificação determinam técnicas distantes da realidade dos gestores e não fornecem regras operacionais a serem seguidas. Assim, os gerentes podem ser induzidos a tomar decisões com base em suas experiências e no senso comum, de forma a usar a prática de terminar preços com 99 mesmo sem um embasamento científico. Conforme aponta o estudo de Paixão, Carvalho Júnior e Bruni (2010), a prática de preços fracionários, principalmente os terminados em 8 e 9 , é comum entre varejistas, porém não há conclusões efetivas do motivo por que tal prática acontece.

Várias pesquisas internacionais analisaram essa prática de precificação. Exemplo disso é o estudo de Anderson e Simester (2003), que verificou um efeito positivo de preços terminados em 9 na demanda. Segundo os autores, uma das explicações para esse fenômeno é a ancoragem do dígito esquerdo.

A pesquisa feita por Guéguen et al. (2009) mostrou que é mais provável que um cliente escolha um item cujo preço termina em 99 do que um cujo preço termina em 00. Porém, isso só ocorre quando estão misturados preços terminados em 00 e 99. Tal fenômeno também poderia ser explicado pela teoria da ancoragem do dígito esquerdo. No contexto do e-commerce, Hackl, Kummer e Winter-Ebmer (2014) identificaram que a fixação dos preços terminados em 9 pode ser lucrativa, uma vez que pode-se passar a impressão de que o preço está abaixo do limiar máximo que os consumidores estão dispostos a pagar.

Há também o estudo de Schindler (2006), indicando evidências da relação entre preços terminados em 99 e a interpretação de preço baixo. A pesquisa identificou que grande parte dos preços terminados em 99 são usados pelos varejistas em mercadorias como uma estratégia de marketing, a fim de persuadir o consumidor de que os preços ofertados são bons.

De acordo Cardoso e de Oliveira (2005), esses preços também podem causar uma opinião negativa nos consumidores. Na hora do recebimento do troco, por 
Precificação de Produtos e Ancoragem do Dígito Esquerdo: uma Análise da Percepção de Futuros

Gestores

José Lucas Lara de Melo, Fernanda Francielle de Oliveira Malaquias, Alexsandra Faria da Silva, Ana

Carolina Alves de Souza, Marcielle Cristina Pessoa Ribeiro

exemplo, muitos estabelecimentos não têm moedas no valor suficiente para poder devolver a quantidade correta de troco.

O preço também pode influenciar na percepção de qualidade dos produtos, de modo que preços mais baixos tendem a passar a imagem de um produto de menor qualidade (SCHINDLER, 2006). O estudo realizado por Schindler e Kibarian (2001) sugere que, se, por um lado, preços terminados em 99 transmitem uma imagem favorável ao anunciante porque passam uma imagem de desconto, por outro lado, eles também podem reduzir a percepção da qualidade do item anunciado.

Macé (2012) identificou que uma prática indiscriminada de fixação de preços em 99 nem sempre é efetiva, podendo levar inclusive à perda de vendas. Segundo o autor, esse tipo de preço não se mostra efetivo para aumentar as vendas de grandes marcas. Os estudos anteriores evidenciam que a exploração da Ancoragem do Dígito Esquerdo pode ter efeitos tanto positivos quanto negativos para as empresas. Os resultados obtidos com a realização desta pesquisa visam contribuir com o panorama apresentado, uma vez que a ancoragem do dígito esquerdo foi analisada com base na percepção de futuros gestores.

\section{METODOLOGIA}

Para a realização desta pesquisa, foi adotada a abordagem qualitativa. Segundo Minayo (2001), este tipo de pesquisa permite que seja feita uma análise mais aprofundada de fenômenos, dando maior compreensão a eles, permitindo, pois, que o objetivo do presente artigo, que é entender como os estudantes de Administração veem a exploração da ancoragem do digito esquerdo na precificação de produtos, fosse atingido. Quanto aos objetivos, trata-se de uma pesquisa descritiva, já que busca especificar e descrever as características do grupo ou a realidade analisada (SAMPIERI; COLLADO; LUCIO, 2013).

A coleta de dados foi realizada por meio de entrevistas semiestruturadas. Essa técnica de coleta de dados possibilita a verificação de diferentes perspectivas sobre um 
Precificação de Produtos e Ancoragem do Dígito Esquerdo: uma Análise da Percepção de Futuros

Gestores

José Lucas Lara de Melo, Fernanda Francielle de Oliveira Malaquias, Alexsandra Faria da Silva, Ana

Carolina Alves de Souza, Marcielle Cristina Pessoa Ribeiro

fenômeno. Sua característica semiestruturada permite que as diferentes entrevistas sejam comparadas entre si, sem que seja perdida a possibilidade da flexibilização.

As entrevistas foram realizadas com estudantes do curso de Administração de uma universidade pública do estado de Minas Gerais, selecionados pelo método de amostragem não probabilística por conveniência. Conforme apontado por Sampieri, Collado e Lucio (2013), as amostras por conveniência são comumente utilizadas em estudos qualitativos e correspondem a amostras compostas por casos disponíveis aos quais tem-se acesso. O tamanho da amostra foi estabelecido durante o processo de coleta dos dados, quando houve a saturação das respostas. Percebeu-se a saturação após a realização de 8 entrevistas.

As entrevistas foram gravadas, transcritas e posteriormente analisadas por meio da Análise de Conteúdo, que é uma técnica de análise utilizada quando se deseja descrever o conteúdo de alguma forma de comunicação e que pode ser definida como:

Um conjunto de técnicas de análise das comunicações visando obter por procedimentos sistemáticos e objetivos de descrição do conteúdo das mensagens indicadores (quantitativos ou não) que permitam a inferência de conhecimentos relativos às condições de produção/recepção (variáveis inferidas) destas mensagens (BARDIN, 1977, p. 42).

A análise do conteúdo das entrevistas foi realizada com o auxílio do software NVivo, no qual os trechos das entrevistas foram codificados e depois agrupados em categorias para serem, por fim, relacionados com a teoria.

\section{ANÁLISE DOS RESULTADOS}

Foram entrevistadas 5 mulheres e 3 homens, na faixa etária de 19 a 23 anos. Todos cursavam Administração e estavam entre o $3^{\circ}$ e 0 7ํㅜㄹ períodos. Cinco dos entrevistados trabalhavam em uma empresa Júnior de consultoria empresarial, um trabalhava na área financeira de uma organização estudantil, um atuava como instrutor de ensino e outro como operador de telemarketing. 
Precificação de Produtos e Ancoragem do Dígito Esquerdo: uma Análise da Percepção de Futuros

Gestores

José Lucas Lara de Melo, Fernanda Francielle de Oliveira Malaquias, Alexsandra Faria da Silva, Ana

Carolina Alves de Souza, Marcielle Cristina Pessoa Ribeiro

Do conteúdo das entrevistas, foram extraídos os principais pontos-chave que foram codificados e, posteriormente, agrupados em três categorias: C1 - Imagem passada; C2 - Intuição; e C3 - Exploração da Ancoragem do Dígito Esquerdo.

\subsection{Imagem passada}

A análise do conteúdo evidenciou que, na percepção dos estudantes, a precificação decorrente da ancoragem do dígito esquerdo gera uma imagem de preços menores para os clientes, de modo que parece que o produto se encontra em promoção ou está com alguma espécie de desconto.

E1: Sim, as empresas colocam $R \$ 10,99$ ao invés de colocar $R \$ 11$, o que [...] influencia as pessoas a comprar mais [...] porque elas têm uma percepção de que é mais barato do que se fosse $R \$ 11$.

E4: Em supermercado geralmente todos os produtos terminam em 99 pra dar a impressão de que é mais barato do que ele realmente é.

E2: Porque a pessoa é levada a pensar que o preço é mais barato.

Tal imagem de preço menor pode ser associada ao próprio conceito da Ancoragem do Dígito Esquerdo, que faz com que o consumidor olhe o valor mais à esquerda e se esqueça dos valores quebrados que se encontram mais à direita da informação numérica (PAIXÃO; CARVALHO JÚNIOR; BRUNI, 2010). Esse dado extraído da análise de conteúdo encontra também respaldo no estudo de Schindler e Kibarian (2001), que mostrou que os preços terminados em 99 dão a impressão de serem mais baratos, de maneira que o consumidor pensa que não conseguirá achar um preço menor nos concorrentes.

Há ainda o fato de que preços terminados em 99 passam a imagem de preços mais baixos (SCHINDLER, 2006). Desse modo, pelo preço baixo, há uma associação entre esse tipo de preço e os varejos de massa, que são aqueles que possuem um baixo mark-up, mas um alto volume de vendas (KOTLER; KELLER, 2013). O trecho de entrevista abaixo evidencia esse tipo de impressão passada pelos produtos com preço terminado em 99. 
Precificação de Produtos e Ancoragem do Dígito Esquerdo: uma Análise da Percepção de Futuros

Gestores

José Lucas Lara de Melo, Fernanda Francielle de Oliveira Malaquias, Alexsandra Faria da Silva, Ana Carolina Alves de Souza, Marcielle Cristina Pessoa Ribeiro

E7: No geral quando é um produto mais... menos sofisticado, as empresas costumam colocar esse tipo de precificação para ele aparentar ter um preço mais baixo. Principalmente produtos que sofrem guerras de preços frequentes. Então produtos de supermercado que as pessoas sempre ficam comparando. Então eles sempre usam esse 99 no final para parecer que é mais barato que o da concorrente. [...] Agora produtos mais sofisticados, este tipo de precificação não é adequado porque a pessoa entende que é um preço... é uma má precificação para aquele produto. Como se aquele produto não merecesse aquele preço.

Apesar de os estudantes, de um modo geral, considerarem positivo esse tipo de precificação, muitos deles apontaram um ponto negativo no que se refere ao troco, pois o cliente nem sempre tem seu dinheiro devolvido. Essa visão negativa dos consumidores sobre a falta de troco nos varejos já havia sido apontada por Cardoso e de Oliveira (2005). Como a quantia a ser ressarcida é muito pequena, muitos estabelecimentos não devolvem o troco, ocasionando uma imagem negativa desses preços e fazendo com que o consumidor se sinta lesado.

E8: Assim... como consumidor eu preferiria... que fosse os valores integrais, porque eles não estão me devolvendo os meu "um centavo", "dois centavos" de troco.

E7: Então ele tá enganando o cliente fácil. Mas se ele se comprometer a voltar o troco, para mim é uma precificação normal. Acho que é mais isso que me incomoda. Porque no geral esse preço...é... quebrado ele só é colocado pro cliente ter uma percepção de preço mais baixo.

Quando perguntado a opinião dos alunos, enquanto consumidores, sobre o uso de preços terminados em 99, alguns dos entrevistados afirmaram que, atualmente, não realizam mais o procedimento de simplificação da informação. Eles passaram a arredondar para cima os valores dos preços, de modo a obter um preço final mais representativo daquilo que será pago efetivamente por ele.

E2: Olha antigamente eu tinha a sensação que era mais barato mesmo, mas hoje eu vejo com outros olhos esses 1,99; 2,99 e eu já consigo imaginar que o preço não é 2 é 3 porque está muito mais próximo de 3 , e eles não vão me devolver 1 centavo 
Precificação de Produtos e Ancoragem do Dígito Esquerdo: uma Análise da Percepção de Futuros

Gestores

José Lucas Lara de Melo, Fernanda Francielle de Oliveira Malaquias, Alexsandra Faria da Silva, Ana

Carolina Alves de Souza, Marcielle Cristina Pessoa Ribeiro

de troco. Então eu olho isso hoje né, depois de todos esses anos aí, é... eu olho isso muito mais como uma estratégia utilizada para vender mais, mais eu não caio nessa.

Essa perda de eficácia pode ser relacionada com o estudo de Macé (2012) que identificou que uma prática indiscriminada de fixação de preços em 99 nem sempre é efetiva e de Guéguen et al. (2009), que revelou que a atratividade dos preços terminados em 99 é maior quando estes estão misturados com preços terminados em 00 .

Os entrevistados também apontaram que, devido à massiva utilização dos preços quebrados, há uma falta de preços redondos no mercado, comprometendo a ocorrência da ancoragem do dígito esquerdo.

E8: Todo comércio que vamos hoje em dia em qualquer lugar, você não acha os preços integrais. É sempre preços picados, sempre \$0,99, \$1,43.

E5: Então, eu acho que isso é mais pelo fato de isso já fazer parte do cotidiano. Hoje é muito difícil a gente ver um produto ou um preço assim arredondado. É sempre quebrado, tem sempre esses centavos.

Os resultados dessa categoria apontam que, embora os estudantes entrevistados apresentem uma visão, em maior parte, positiva sobre esse tipo de precificação, demonstrando crenças de que ela influencia os clientes a comprarem mais devido à imagem de um preço mais baixo, eles também apontam aspectos que podem tornar a exploração da ancoragem do dígito esquerdo menos eficiente.

\subsection{Intuição}

Os entrevistados mostraram, ao longo de suas entrevistas, a crença de que os gestores de empresas de menor porte tomam a decisão de colocar preços terminados em 99 a partir da intuição, baseando a decisão de precificação a partir de suas próprias impressões dos preços. Eles também acreditam que as empresas adotam tal estratégia de precificação como uma forma de acompanhar as empresas de maior porte, que possuem maiores recursos e capacidade de tomar uma decisão racional.

E7: Eu acho que é muito na intuição sabe? [...] Eles entendem os efeitos que tem, que as pessoas vão ver o preço menor [...] mas eles não sabem a teoria por trás 
Precificação de Produtos e Ancoragem do Dígito Esquerdo: uma Análise da Percepção de Futuros

Gestores

José Lucas Lara de Melo, Fernanda Francielle de Oliveira Malaquias, Alexsandra Faria da Silva, Ana Carolina Alves de Souza, Marcielle Cristina Pessoa Ribeiro

daquilo, quando é mais adequado ou inadequado. Eles simplesmente usam por senso comum eu acho.

E5: Então, as grandes empresas eu acho que conhecem sim, agora geralmente micro e pequenas empresas assim, não conhecem. Mas de tanto eles verem os outros varejos utilizando, as grandes empresas utilizando, eles acabam imitando e usando essa técnica, eu acho que inconscientemente mesmo na hora de precificar o produto.

Isso está de acordo com o que afirma Motta (1998), segundo o qual, no atual cenário da Administração, há uma dificuldade em se tomar decisões inteiramente racionais, havendo o uso da intuição. E, segundo Diamantopoulos (2003), os métodos de precificação definidos pelos pesquisadores muitas vezes não são praticáveis na realidade das organizações, o que reforça a tomada de decisão intuitiva.

\subsection{Exploração da Ancoragem do Dígito Esquerdo}

Quando perguntado aos estudantes se eles explorariam a ancoragem do dígito na precificação dos produtos caso eles tivessem uma empresa de varejo, todos afirmaram que sim. Eles acreditam que, usando essa estratégia, poderiam atrair mais consumidores.

E1: Porque eu acho que iria conseguir mais clientes do que se eu não colocasse essa diferença de 1 centavo. Uma coisinha que no final não faz tanta diferença, mas leva o cliente ao consumo.

E5: Ah, eu usaria. Porque ela, como já foi comprovado, ela chama mais a atenção do consumidor. Eu vi isso em uma matéria de psicologia. Então eu utilizaria sim porque [...] as vezes um produto quando você coloca o preço de 99,90 ao invés de 100 reais, esses 10 centavos a menos para minha empresa seria compensado no volume de vendas.

Em decorrência da imagem que os produtos precificados com base na ancoragem do dígito esquerdo passam, os entrevistados mostraram a crença de que haveria um incremento de resultados e aumento das vendas. 
Precificação de Produtos e Ancoragem do Dígito Esquerdo: uma Análise da Percepção de Futuros

Gestores

José Lucas Lara de Melo, Fernanda Francielle de Oliveira Malaquias, Alexsandra Faria da Silva, Ana

Carolina Alves de Souza, Marcielle Cristina Pessoa Ribeiro

E6: Para aumentar minhas vendas, porque se eu colocar o valor 100,00 reais assusta o cliente, mas se eu colocar 99,99 já não é tão assustador. Então acredito que é uma boa estratégia.

E2: Acho que cabe uma pesquisa bastante interessante sobre isso, mais eu particularmente acredito que surgem alguns efeitos sim nas vendas.

E5: Se você entrar no supermercado é muito difícil de achar um produto com um preço de 3 reais, 4 reais, tem sempre um número menor assim do lado. Então, eu acho que essa tática que eles utilizam traz mais resultados e eu tenho certeza que aumenta o volume de vendas para empresa.

Por fim, a maioria dos estudantes acredita que a tática de utilizar preços terminados em 99 funciona apenas para determinados tipos de varejo.

E6: Acredito que só em alguns... voltados mais para classe $C$.

E3: Ah porque tem algumas pesquisas que falam isso, esses 99 são típicos de produtos que são mais baratos. Então, em produtos mais caros não fazem muita diferença.

As evidências observadas por meio das entrevistas realizadas somam-se aos resultados de pesquisas anteriores (como DIAMANTOPOULOS, 2003; PAIXÃO; CARVALHO JÚNIOR; BRUNI, 2010; ANDERSON; SIMESTER, 2003; GUÉGUEN et al., 2009; HACKL; KUMMER; WINTER-EBMER, 2014; SCHINDLER, 2006), indicando que existe uma percepção intuitiva, por parte de quem pratica esta estratégia de ancoragem do dígito esquerdo, de que os vieses comportamentais que guiam as decisões dos consumidores podem ser o caminho para que as empresas alcancem melhores indicadores de rentabilidade.

\section{CONSIDERAÇÕES FINAIS}

O objetivo geral deste estudo consistiu em evidenciar como os estudantes de Administração, enquanto futuros gestores, percebem a exploração da ancoragem do dígito esquerdo na precificação de produtos. Para tanto, foi adotada uma abordagem 
Precificação de Produtos e Ancoragem do Dígito Esquerdo: uma Análise da Percepção de Futuros

Gestores

José Lucas Lara de Melo, Fernanda Francielle de Oliveira Malaquias, Alexsandra Faria da Silva, Ana Carolina Alves de Souza, Marcielle Cristina Pessoa Ribeiro

qualitativa, tendo sido entrevistados alunos matriculados no curso de Administração de uma universidade pública do estado de Minas Gerais. Esses alunos foram selecionados por representarem os futuros gestores ou profissionais que irão auxiliar os gestores na formação do preço de venda dos produtos.

Por meio da análise do conteúdo das entrevistas, concluiu-se que os estudantes de Administração veem os preços decorrentes da ancoragem do dígito esquerdo como uma estratégia válida que eles adotariam caso tivessem uma empresa de varejo para aumentar o volume de vendas. De acordo com os entrevistados, tais preços criam a imagem de um produto mais barato, sendo, portanto, mais persuasiva. Esses estudantes associam tal precificação como pertencente a varejos de massa, que são caracterizados por produtos de menor valor e que sofrem maior concorrência de preços.

Os entrevistados também veem essa precificação como uma prática fortemente intuitiva em comércios de pequeno porte. Porém, no que se refere a grandes varejos, eles veem essa precificação como planejada e intencional. É importante salientar que, embora a adoção da ancoragem do dígito esquerdo seja utilizada de forma intuitiva, os gestores e proprietários das empresas devem considerar que a formação do preço de venda deve fundamentalmente considerar os custos necessários para a formação de um produto. Com essa informação, pode-se verificar se existem ineficiências e quais alternativas podem ser adotadas para a melhoria do resultado de uma determinada empresa. O principal argumento, então, neste artigo, é de que a precificação com base na ancoragem do dígito esquerdo trará melhores resultados quando combinada com os princípios da contabilidade gerencial e gestão de custos.

Por fim, os estudantes indicaram como ponto negativo dessa precificação o troco que, nem sempre, é devolvido, pois eles sentem que essa é uma ação lesiva ao consumidor e que pode gerar uma atitude negativa para com os produtos e varejos que adotam esse tipo de preço.

Destaca-se que, diferentemente da maioria dos estudos anteriores que analisam esse tipo de precificação sob a ótica dos consumidores, o presente estudo analisa essa 
Precificação de Produtos e Ancoragem do Dígito Esquerdo: uma Análise da Percepção de Futuros

Gestores

José Lucas Lara de Melo, Fernanda Francielle de Oliveira Malaquias, Alexsandra Faria da Silva, Ana

Carolina Alves de Souza, Marcielle Cristina Pessoa Ribeiro

forma de precificação sob a ótica de futuros gestores. Além disso, o uso da abordagem qualitativa permitiu uma análise mais aprofundada do tema em questão.

Como estudo futuro, sugere-se a realização de uma pesquisa com empresários e/ou gestores responsáveis pela formação de preços com o objetivo de compreender a adoção desse tipo de precificação na percepção dos mesmos. Esta proposta de novo estudo poderá indicar se a exploração da ancoragem do dígito esquerdo se dá de maneira intuitiva ou intencional. Além disso, novos estudos podem analisar o efeito de características dos gestores, potencialmente relacionadas com o uso dessa estratégia.

\section{REFERÊNCIAS}

AHMETOGLU, G.; FURNHAM, A.; FAGAN, P. (2014). Pricing Practices: A critical review of their effects on consumer perceptions and behavior. Journal of Retailing and Consumer Services, 21(5): 696-707.

ANDERSON, E. T.; SIMESTER, D. I. (2003). Effects of \$9 Price Endings on Retail Sales: Evidence from Field Experiments. Quantitative Marketing and Economics, 1: 93110.

BLACKELL, R. D.; MINIARD, P. W.; ENGEL, J. F. (2005). Comportamento do consumidor. (9. ed.). São Paulo: Cengage Learning, 632 p.

BARDIN, L. (1977). Análise de conteúdo. Lisboa: Edições 70.

BAPTISTA, M. A.; SILVA, A. J.; ALVAREZ, F. H. B. (2016). Custos de Produção de Artigos Têxteis e Avaliação da Possibilidade de Terceirização da Fabricação após a Reorganização do Arranjo Físico. ABCustos, 11(2): 49-71.

CARDOSO, L. S.; DE OLIVEIRA, N. S. (2005). Análise dos Circuitos da Economia em Serrinha, In: ENCONTRO BAIANO DE GEOGRAFIA, 8, Vitória da Conquista, 2005, Anais... Vitória da Conquista, UESB.

CARVER, J. R.; PADGETT, D. T. (2012). Product Category Pricing and Future Price Attractiveness: 99-Ending Pricing in a Memory-Based Context. Journal of Retailing. 88(4): 497-511.

DIAMANTOPOULOS, A. (2012). Pricing. In: BAKER, M. (Org.) The Marketing Book. (5. ed.). Oxford, Butterworth-Heinemann. 
Precificação de Produtos e Ancoragem do Dígito Esquerdo: uma Análise da Percepção de Futuros

Gestores

José Lucas Lara de Melo, Fernanda Francielle de Oliveira Malaquias, Alexsandra Faria da Silva, Ana

Carolina Alves de Souza, Marcielle Cristina Pessoa Ribeiro

GUÉGUEN, N. et al. (2009). Nine-ending prices and consumer's behavior: A field study in a restaurant. International Journal of Hospitality Management, 28(1): 170-172.

HACKL, F.; KUMMER. M. E.; WINTER-EBMER, R. (2014). 99 Cent: Price points in ecommerce. Information Economics and Policy, 26:12-27.

OTLER, P.; KELLER, K. (2012). Administração de Marketing. (14. ed.). São Paulo, Pearson Education do Brasil, 792p.

LEONE, G. S. G.; LEONE, R. J. G. (2007). Os 12 mandamentos da gestão de custos. Rio de Janeiro: Editora FGV.

MACÉ, S. (2012). The Impact and Determinants of Nine-Ending Pricing in Grocery Retailing. Journal of Retailing, 88(1): 115-130.

MARCELINO, C. V.; BRUNI, A. C. (2013). O viés da cognição numérica e seus reflexos nas decisões contábeis. Revista Ambiente Contábil, Natal, 5(1): 39 - 54.

MARTINS, E. (2003). Contabilidade de Custos. (9. ed.). São Paulo, Atlas.

MILAN, G. S.; TONI, D.; de. LARENTIS, F.; GAVA, A. M. (2013). Relação entre estratégias de preços e de custeio. Revista de Ciências da Administração,15(36): 229244.

MINAYO, M. C. de S. (2001). (Org.) Pesquisa social: Teoria, método e criatividade. (19. ed.). Petrópolis, Vozes.

MOREIRA, A. K. X. A.; OLIVEIRA, C. A. G. da.; FURLAN, P. V. D.; BRITO, E. de.; GAIO, L. E. G. (2015). Determinantes dos Custos em Empresas do Setor Moveleiro. ABCustos, 10(1): 51-72.

MOTTA, P. R. (1988). Razão e Intuição: Recuperando o ilógico na teoria da decisão gerencial. Revista de administração pública, 22(3): 77-94.

PAIXÃO, R. B.; CARVALHO JÚNIOR, C. V. de O.; BRUNI, A. L. (2010). Heurísticas e ancoragens na formação dos preços em supermercados. Rege, 17(4): 437-450.

SAMPIERI, R. H.; COLLADO, C. F.; LUCIO, M. P. B. (2013). Metodologia de Pesquisa. (5 ed.). Porto Alegre, AMGH, $624 \mathrm{p}$.

SCHINDLER, R. M. (2006). The 99 price ending as a signal of a low-price appeal. Journal of Retailing, 82(1): 71-77. 
Precificação de Produtos e Ancoragem do Dígito Esquerdo: uma Análise da Percepção de Futuros

Gestores

José Lucas Lara de Melo, Fernanda Francielle de Oliveira Malaquias, Alexsandra Faria da Silva, Ana

Carolina Alves de Souza, Marcielle Cristina Pessoa Ribeiro

SCHINDLER, R. M.; KIBARIAN, T. M. (2001). Image Communicated by the Use of 99 Endings in Advertised Prices. (Journal of Advertising), 30(4): 95-99.

SILVA FILHO, L. L. SILVA FILHO, L. L.; LAGIOIA, U. C. T.; ARAÚJO de, J. G. N.; ARAUJO de, J. G.; CARLOS FILHO, F. A. C. (2015). Gestão de Custos e Formação de Preço de Venda, Gestão de Caixa e Gestão de Riscos: um estudo exploratório no arranjo produtivo local gesseiro do estado de Pernambuco. ABCustos, 10(3): 107-142.

TONI, D.; SCHULER, M. (2007). Gestão da imagem: desenvolvendo um instrumento para a configuração da imagem de produto. Revista de Administração Contemporânea, 11(4): 131-151.

TORRES, U. P. P.; MARTINS, H. C. (2006). Análise estratégica das áreas de marketing e finanças no processo de formação e manutenção dos preços: o caso da montadora Fiat Automóveis S. A. In: Encontro de Marketing da ANPAD, (2. ed.). Rio de Janeiro, 2006, Anais... Rio de Janeiro, ANPAD.

WIENHAGE, P.; ROCHA, I.; SCARPIN, J. E. (2012). Aplicação do Target Costing e Engenharia de Valor na Precificação de Curso de Pós-Graduação. ABCustos, 7(1): 87 111.

Data de Submissão: 20/07/2016

Data de Aceite: 12/12/2016 